\title{
Who's Afraid of the Big, Bad Wolf? \\ Young People's Responses to the Conflicts Over large
}

Carnivores in Eastern Norway

Published in Rural Sociology (2001) Vol 66, No 2: 203-226

Ketil Skogen, Norwegian Social Research, NOVA

ketil.skogen@nina.no

Department of Sociology and Human Geography University of Oslo

P.O.Box 1096 Blindern

N-0317 OSLO Norway

Telephone: $\quad+4722855257$

Fax: $\quad+4722855253$

Internet: http://www.iss.uio.no 


\title{
Who's Afraid of the Big, Bad Wolf? Young People's Responses to the Conflicts Over Large Carnivores in Eastern Norway*
}

\author{
Ketil Skogen \\ NOVA-Nonvegian Social Research, Oslo
}

Abstract Controversies over large carnivores are often interpreted as clashes between rural traditionalism and urban modernity. Rural communities, however, have never been culturally monolithic, and modernization will increase the diversity. To probe such diverse and changing attitudes towards nature, I conducted a qualitative study of young people in a rural community in eastern Norway. Contrary to popular images of such communities as unified against "pests," all typical views of the carnivore issue were present. Those in favor of the large carnivores were typically middle-class youths with a strong "outward" orientation, while those who wanted to shoot the predators were mostly working-class boys with strong ties to the local hunting culture. This pattern was interpreted as a conflict between dominant and subordinate forms of knowledge, and between abstraction-oriented and production-oriented cultural forms. Aside from the growth of the pro-carnivore middle-class segments, the most significant effect of modernization appeared to be the removal of many young people from the subject matter of the conflict. A "subculturalization" of the working-class hunting culture also could be discerned, however.

After decades of protection, the four species of large carnivores found in mainland Norway (brown bear, lynx, wolverine, and wolf) are now slowly recovering from the brink of extinction. This development is applauded by environmentalists, managers, biologists, and many politicians. Opinion polls also indicate enthusiasm in a majority of the general population. Increasing carnivore populations have spurred fierce conflicts, however. Livestock depredation and competition for huntable game are key issues, but the killing of hunting dogs and the possibility of attacks on people also feature in the controversies.

In the public debate it is often suggested that this is a conflict representing a clash between old and new perspectives on nature, or rural traditionalism and urban modernity. Whereas this seems to touch some core issues, we know little about the operative mechanisms. In particular, we know little of how young people are handling such issues. According to other popular images, supported by current sociological theory on individualization in late

*This research was funded by a grant from the Research Council of Norway, Environment and Development Division. Direct all correspondence to the author at: PO Box 3223, Elisenberg N-0208, Oslo, Norway; phone +47 22541200 ; fax +47 22541201 ; e-mail ketil.skogen@isaf.no. 
modernity, young people are speedily leaving behind all traces of a traditional society. The aim of this paper is twofold: to investigate the diversity of interpretations of the carnivore conflict in a rural community, and to use the handling of this conflict to gauge the influx of social change, particularly on youths in rural areas.

The carnivore conflicts have attracted considerable media interest in recent years. The issue has been construed as extremely central and all-encompassing in affected areas. The media have created an impression of a united local front against current carnivore protection. This picture is corroborated by representatives of organizations associated with farming and hunting, and by most local politicians. The universal theme is that environmentalists, scientists, managers, and politicians, who themselves are city people, and who represent institutions or organizations based outside the affected regions, are forcing large carnivores upon the locals, who are unanimous in their negative opinion of these animals and of the romantic views of nature held by people who have never seen a mutilated sheep.

\section{The Urban-Rural Axis}

Although social scientists also refer to the urban-rural dimension of this conflict, this axis has not been addressed explicitly in Norwegian research on the carnivore conflicts. Actually, recent studies have identified attitude differentiation along axes other than the urban-rural. Bjerke, Reitan, and Kellert (1998) found that approval of wolf protection among people in areas with wolves increased with level of education, and decreased with increases in age and in perceived size of the current wolf population. Kaltenborn, Bjerke, and Strumse (1998) found that pro-carnivore attitudes correlated with general pro-environmental beliefs, and that such beliefs were stronger among biologists and managers than among sheep farmers.

Yet despite the present deficiency in scientific knowledge, it appears that processes of structural and cultural change can be read in harder conflicts over land use and resource exploitation. In Norway, the conflicts over sealing and whaling are prime examples (see Kalland 1993) in addition to the carnivore controversies. In North America, numerous "wise use" organizations have emerged and expanded in the wake of conflicts closely resembling the Norwegian issues (see Echeverria and Eby 1995; Foster 1993; Hanson 1995). Economic centralization, urban growth, and deterioration of traditional rural values seem to underlie the conflict panorama. Thus we must anticipate that the urban-rural axis is important, not least in regard to the social construction of the conflicts: that is, to the involved groups' interpretations of the lines of conflict. 
Even so, it seems unlikely that this dimension in itself can explain the diversity of views and interpretations in the carnivore conflict, or indeed in any other conflict over land use. Economic and cultural modernization has led to increased differentiation and shifting cultural power relations; some of these shifts indeed occur along the urban-rural axis, increasing the dominance of urban areas and urban culture. Yet rural communities are changing as well. Most rural communities are now more economically diversified than in the past: considerable proportions of the population are employed in the service sector, in new manufacturing industries, and in the public sector. Not least, the number of middleclass jobs demanding higher education has increased, significantly changing the educational profile of the workforce. At the same time, employment in agriculture, resource extraction, and related processing industries has declined sharply.

Accordingly, and also because of extensive contact and exchange with urban areas and the evolution of new media, substantial cultural diversification must be anticipated. For a considerable proportion of the population, the utilization of nature is now relegated to leisure. Even customary consumptive outdoor recreational activities may lose their significance because they are traditionally bound to a life of physical interaction with nature, both within and outside the sphere of work. Thus we also must expect considerable diversity in relation to nature, and consequently in attitudes towards resource exploitation.

\section{New (and Not So New) Cultural Forms in Late Modernity}

Many social scientists contend that characteristic features of late modernity increase the need for active identity construction and for expressing identity in clearly visible ways. Old collective identities, rooted in class positions and gender roles now seen as eroded by structural and cultural change, are thought to have lost their grip on individual identity formation. Individuals are left to themselves when facing the formidable task of making an unprecedented range of choices and actively constructing their identities. This situation may be risky and frightening; yet it is often construed as having the potential to emancipate (see Beck 2000; Featherstone 1992; Furlong and Cartmel 1997; Melucci 1996). This shift toward individualization, in combination with the loosening of ties to the exploitation of natural resources, then could be anticipated to exert significant effects on people's attitudes toward nature.

Such processes of change probably will have the most significant impact on young people's lives, not least because fundamental identity formation processes take place in adolescence and early adulthood. Young people seem to be a logical starting point when 
one is probing for cultural change, because signs of such change should be most readily observable among them.

Yet although processes of individualization and cultural differentiation certainly are taking place, the magnitude of these changes is not determined so easily. The stronger versions of theories about the characteristics of "late modernity" seem to have a rather shaky empirical foundation. Several authors have warned against an unwarranted downplaying of the enduring effects of structural factors such as class and gender; such factors, if nothing else, will limit the range of real choices available to sizable groups of young people. For example, Furlong and Cartmel (1997:113) acknowledge that the proponents of theories of "reflexive modernization" and the like have aptly described some significant features of contemporary society, but claim that nevertheless they "have failed to capture the essence of late modernity due to an overemphasis of the significance of individual reflexivity."

Wide-ranging change clearly has occurred in some fields that are quite important to young people. The relatively undifferentiated labor market of early postwar agriculture, resource extraction, and Fordist industry has turned into a differentiated skill market (Bynner, Ferri, and Shepherd 1997; Furlong and Cartmel 1997; Pollock 1997). Yet although this change has transformed not only the labor market itself but also the educational system, empirical research demonstrates that old structures are still at work. Recent Norwegian studies have shown that educational choices and attitudes toward school are heavily influenced by class (Hegna and Helland 1998; Skogen 1998), as are young people's patterns of leisure activity (Skogen 1998).

Nor are young people's attitudes toward nature independent of class background and sociocultural heritage. A recent Norwegian survey demonstrated that young people's environmental orientation was part of a larger cultural package (Skogen 1996, 1998). However, environmental concern that could be tied to worries about individual risk was less culturally specific than concern that was part of a comprehensive critical perspective. A critical attitude toward economic growth, coupled with endorsement of a critical ecological paradigm-particularly joining an environmental organization-was part of a rather narrow cultural package, with a class basis in the "humanistic-social intermediate strata" (HSIS) ${ }^{1}$ in particular.

\footnotetext{
1 The middle class was divided into two fractions in this study. Examples of occupations placed in the HSIS category are physicians, teachers, social workers, and artists, whereas occupations such as engineers, economists, and advertising people were sorted into a category labeled "technical-economic intermediate strata." Parents' occupations were used as a basis for classification.
} 
The culture profiles that formed the most distinct patterns in relation to environmental orientation also did so in relation to class. A strongly environmentalist, politically radical profile had a HSIS affiliation, while a profile that was averse to environmentalists and immigrants alike, and that possessed a distinct macho orientation, was found among young people with a manual workingclass or farming/fishing background. The picture grew even clearer when educational choices and cultural assets were taken into account: those who most strongly endorsed a critical environmental perspective typically came from an HSIS background, had many books in their childhood homes, and chose academic programs in secondary education. Thus the strongest support for a critical ecological paradigm was found among young people socialized in milieus with a strong academic orientation, particularly in those segments of the middle class which are rather detached from, and often perceive themselves as somewhat opposed to, the core processes in capitalist market economy. That is, they have the intellectual power to criticize these processes and their impact on the environment; at the same time, they are not constrained by too obvious a dependence on those processes. This point, then, indicates that the paradigm supplying the ideological basis for the environmental movement has a rather narrow cultural base, although, as environmental concern goes, it apparently has acquired a hegemonic position. This particular paradigm, however, cannot be the only foundation for a close relationship to nature, nor for anxiety about the threats facing nature.

This study provided an interesting picture of relationships between environmental orientation, cultural patterns, and class background. Yet it suffered from the same limitations as all surveys, and can tell us only so much about the cultural dimensions of the issue at hand. Because the concept of culture is largely about meaning, the aim of research in culture must be to interpret such meaning. There is an obvious need for qualitative data that lend themselves to such interpretation. Acquiring such data was the aim of the present study, which was designed to capture some of the deeper cultural structures underlying young people's views and interpretations of environmental issues.

\section{Research Questions}

I investigated two possible axes of differentiation, and the interaction between them. One was the impact of current structural and cultural change on rural young people's relationship to nature and land use in general, and to the carnivore issue in particular. The other was the differentiation of attitudes and interpretations within rural communities which are related to the "old" background factors of class and what we might call sociocultural configurations. To phrase it 
somewhat differently, to what extent, and how, are cultural (and thus also environmental) orientations stemming from the reproduction of established relations of class and power modified by mechanisms of structural and cultural modernization?

\section{Locality and Data Collection}

To examine this question, I sought a locality where two criteria could be met: the presence of a clearly visible conflict over the utilization of natural resources, and an economic diversity which, to some extent, could represent degrees of modernization. The choice fell on the municipality of Trysil in Hedmark County, on the Swedish border in eastern Norway. Trysil has been an arena for conflicts over large carnivores for many years. A few decades ago, when bears started to reappear in southern Norway, wandering in from Sweden, they were seen in Trysil first. Therefore this was one of the first areas to be plagued with sheep depredation in modern times. The lynx population also has grown recently. Roe deer, an attractive game species, is a staple food source for lynx. Lynx therefore are blamed for decreasing the hunting opportunities as well as for killing sheep. Wolverines and wolves appear only sporadically in Trysil, but as the number of wolves in southern Norway increases, many people perceive the possibility of a permanent wolf population as a threat. Not only the sheep farmers but also hunters fearing for their dogs have expressed this anxiety.

Trysil has regularly been viewed as one of the districts in Norway with the strongest opposition to large carnivores and to the various actors advocating their protection. In the winter of 1999, an alliance of influential organizations in Trysil launched a new offensive focusing on the problems caused by current carnivore management, problems allegedly posing a threat to the whole community.

In Trysil, however, farming (with or without sheep) does not contribute much to the economy. The economic backbone of the region is forestry and timber processing, and not least the rapidly expanding tourist industry. Trysil now has one of the largest skiing resorts in northern Europe, with four large hotels and 1,200 cabins. The ski slopes received 640,000 visits in the 1997-1998 season; 70 percent of the visitors came from abroad. This distinctly modern enterprise not only affects the economy but also influences the local way of life. Huge numbers of people from outside Trysil are present throughout the winter; there are a number of shops, restaurants, and bars that otherwise never would have existed; young people have employment opportunities; and the many ski slopes and special snowboard facilities are an attractive leisure resource. However, the impact of the tourist industry is concentrated largely in the center of the municipality, 
with about half of the total population of 7,500 . Several smaller communities have retained close ties to forestry and livestock farming. Trysil therefore presented an opportunity to make contact with youths growing up in a community with a large service sector, as well as with young people growing up at the outskirts of this service-sector economy.

To obtain an overview of the present state of the carnivore conflict as well as the general situation for young people in the area, I enlisted 11 adult key informants. These were teachers, social workers, councilors, police, and representatives of voluntary organizations. Their primary function was to provide a basis for selection of youth informants, as well as establishing contacts with the relevant youth milieus.

The selection of young informants was based partly on information from the adult key informants and partly on my desire to cover largely the same groups that appeared to be significant in the earlier survey (Skogen 1996, 1999). I used the following criteria to select informants: some in academic programs and others in vocational training or working; some participating in organized leisure activities such as music and sports; some with an orientation toward vanguard youth cultural trends; some with a strong affiliation with local hunting and fishing traditions; some from the center of the municipality and others from smaller communities; some with sheep farmer parents, as well as some with workingclass and others with middle-class parents; and, of course, both boys and girls.

Data were collected through focus group sessions and interviews with individual informants. The group sessions were conducted in relatively homogeneous groups, so as to let the cultural differences between the groups appear as distinctly as possible. These, however, were all "naturally" existing groups: for example, attendees at a meeting of the junior section of a hunting and fishing association, a complete rock group and a group of brass band members interviewed immediately after practice sessions, and so on. Some key informants were interviewed separately for practical reasons. Others I regarded as "gate openers;" therefore I wished first to establish rapport with them individually. The latter informants were present at "their" group sessions, but kept a low profile there.

The interviews were fairly open-ended, but some core topics were covered in all of them, particularly pertaining to land use, environmentalism, outdoor recreation, and more general issues such as education, employment, and the situation for young people in Trysil. There were 31 informants altogether: 26 of these were interviewed in seven focus groups, and five were interviewed separately. Most were between 16 and 20 years old, roughly the same age group as in the survey. 


\section{Young in the Middle of the Forest}

Before I proceed to the carnivore issue, let me present a brief sketch of some key elements of young people's lives in Trysil. Outdoor recreational activities in some form were important to many-probably most-of the young people. The level of activity varied a great deal, but apparently there were few who did not take part in any type of outdoor recreation. Many used the ski slopes in the winter, and a distinct subculture of snowboarders had developed. The core of this milieu was probably just as avantgarde as anything one could find elsewhere, in Norway or abroad. The snowboarders represented a complete youth cultural package, with distinctive styles of music, dress, and so on. Indeed, this group contained a substantial influx of "ski bums," although the majority were locals. A great enthusiasm for snowboarding had developed around this "authentic" core. Almost everybody seemed to own a board, and snowboarding had all but replaced ordinary downhill skiing.

To some extent, however, the traditional activities of hunting and fishing held their ground, especially among boys. But enthusiasm for hunting in particular appeared to be declining, and many young men in Trysil did not hunt. This appeared to be a rather new development. Also, the core hunting milieus seemed to be regarded more as distinct subcultures than in the past, and were even viewed a little scornfully by the outwardly oriented modernists. Fishing had a slightly different history: although most hunters also fished, many others now only fished. New forms of fishing-for example, modern fly fishing-actually may constitute a departure from a traditional consumptive outdoor recreation culture, where hunting and fishing and a tough, masculine image of "the outdoorsman" are bundled together conceptually.

Cross-country skiing was still relatively popular, although it apparently had suffered a decline; many young people now did this only a few times each year. During the summer, camping, swimming, and exercising dogs were important activities. Few, however, went for walks without any purpose. Many informants said that living in the middle of the forest (as even those who lived in the center of the municipality felt they did) made them take it for granted. Thus going for walks to look at it was viewed as rather irrelevant, and was considered a decidedly city activity.

Young people in Trysil, however, were also (and predominantly) involved in a great variety of leisure activities that could have taken place anywhere: sports (football/soccer being the most popular beside snowboarding), music (everything from avant-garde rock to classical music), drama, and naturally the very important activity of "doing nothing," as Corrigan (1979) aptly labeled that 
part of the young people's rich social life which has no explicit purpose.

\section{Attitudes Toward the Carnivore Conflict}

Views regarding the carnivore issue divided the informants roughly into three categories, although of course there were many shades and nuances. These categories, or typical positions, are meant as analytical tools.

One group was strongly opposed to current carnivore management. The more extreme actually wanted to exterminate the large carnivores; most, however, said they only wanted to decimate populations perceived as far too large. Their view was that all native species should have a place in Norwegian nature, but that things were now getting out of hand. The reason given for this was that environmentalists and biologists (roughly seen as one group) and city people in general had far too much power, and now were using this power to turn rural Norway into a game preserve. Because of ignorance and indifference on the part of powerful organizations and government agencies based in cities, the voices of local people were not heard. The following comment was made by a 20-year-old male who was an active member of a hunting and fishing association, and planned to take over his parents' farm:

I think that those who are most eager to protect them [are] city people ... who haven't been close and seen what [the predators] do, but they only want them to be in Norwegian nature, so they can watch it on TV and read about it in papers.

The boys were most outspoken, but some girls also expressed concern for farmers who lost their sheep and anxiety lest the big predators eventually might attack children.

Second, and in contrast to the prevalent media picture of unanimous opposition to carnivores, some informants also expressed strong pro-carnivore views. They held that large carnivores have the same right to roam Norwegian forests as any other animal (and actually more right than people and sheep), and that everybody should be happy when species that belong in our forests return. In some cases, this set of attitudes also included rather low opinions of sheep farmers and hunters, as well as simplistic ideas about animal rights.

Such views did not necessarily entail a strong, direct engagement in the conflict. The carnivore question did not seem to be discussed frequently by most young people. Thus it was possible to harbor strong opinions without confronting those who disagreed. The following remarks were made by an 18-year-old female informant who was part of the "snowboard scene" and who was en- 
rolled in an academic program in school (her parents belonged to the public-sector middle class): ${ }^{2}$

Int: But aren't there many people here in Trysil who think that there are far too many predators?

Inf: Far too many? I can't understand that!

Int: Well, I guess they kill sheep and that sort of thing

Inf: Yes, but this really pisses me off? In old times they looked after their sheep. Why can't they do that now? They only sit on their fat asses and drive those stupid tractors.

Int: Yes. That's a good one. (laughs)

Inf: But it's true, isn't it. It irritates me. That they should have to shoot predators just because they [kill other animals] no, that's just a fact of life.

A young man of 17 , a soccer player, in academic training, with a father in forestry (with a forestry education) and a mother who worked in public health, spoke as follows:

As I see it, it's the predators that should be in the forest, and not the sheep. Because when predators see a bunch of sheep in the forest, then it's like stealing candy from kids. ... The sheep are so stupid they only run round and round, so it's not difficult to catch them either.

Third, and also at odds with the dominant account of rural carnivore sentiments, the majority of informants generally supported current management practices. That is, they felt that there should be room for both sheep and predators, exactly what the current official policy aims to achieve. Further, they believed that hunters ought to appreciate nature as a whole, and should not focus solely on huntable species. Their reasons for such a position were not uniform, however. For some, this view was based on serious consideration. Some were hunters and outdoorsmen who thought that carnivores should be present in substantial numbers; yet they were critical of "extremist" environmentalism. Others had not thought much about the issue, but seemed to feel that a pragmatic position was the most appropriate-and probably least demanding. They perceived the matter, however, as not highly relevant to themselves. It seemed an issue of the same type as the greenhouse effect or acid rain: they rarely thought about it (un-

2 The occupational classification outlined in note 1 cannot be followed through in the description of each informant because of the risk of disclosing identities. More approximate sketches of informants' class background therefore must suffice. 
less something special brought it to mind), but they managed to produce roughly politically correct answers.

Thus the picture presented by many informants was that the carnivore issue was quite distant and was rarely discussed. Not only was the conflict itself perceived as irrelevant; the informants also associated it with old people, farmers, and hunters to convey an impression that they wanted to keep such old-fashioned issues with a certain redneck flavor at arm's length. Parties on the other side of the conflict-the environmentalists, managers, and biologists-were generally not mentioned except by those who were strongly involved in the conflict: that is, mostly by the ardent carnivore adversaries. Most informants had extremely vague ideas about these groups, and about what they might stand for.

\section{Persistent Cultural Cleavages}

The distribution of views on the carnivore issue roughly corroborated the axis of differentiation identified in the survey cited above (Skogen 1996, 1999). The most ardent carnivore adversaries all had a working-class or farming background and were either working or in vocational training at the time of the interview. Thus, class background indeed seemed to influence attitudes, but not only (or even principally) through tangible economic interests. As we shall see presently, some of the most outspoken carnivore antagonists had no connections to livestock farming, and did not mention sheep at all. Factors other than direct economic interests were obviously at work here.

As noted above, those with the most explicit anti-carnivore views were all males. As a common denominator, they also had a strong attachment to the local hunting, fishing, and outdoors culture. These cultural forms are prevalent in most rural communities, where hunting and fishing traditionally have been important to all social groups. But essential cultural elements, particularly the tough, physical masculinity that is part of the outdoorsman ethos, bear a distinct working-class stamp. We will return to this point presently. Here is it sufficient to say that many young hunters in Trysil were strongly aware of their connections to a traditional, masculine way of life in the forest.

The following remarks were made by a 19-year-old hunter and fisherman who had a working-class background but was in academic training himself. This particular informant actually held moderate opinions on the carnivore issue; being rather verbal, however, he nicely captured the essence of an outdoorsman culture.

Int: $\mathrm{OK}$, so what do you do when you're out?

Inf: We live as huntsmen [using the archaic Norwegian term veidemannsliv to actively connote deep tradition]. A 
little old-fashioned, perhaps. Often we go ice-fishing [the interview took place in midwinter]. We follow the seasons-all kinds of things! In the winter we fish, and often go for longer trips into the mountains to fish for mountain trout. Sleeping outdoors. In the summer we sleep outdoors too, or we spend the nights in old logging cabins. We fish. And in the fall there's nothing but hunting, all possible kinds of hunting. Everything from birds and hare to moose.

Closely connected to the negative attitudes toward carnivores was a resentment toward people who want to protect them. These sentiments sometimes overshadowed the dislike of the animals themselves. Although most informants had very vague ideas about environmentalists, it was not difficult to discern the deep skepticism that was present even among those who refrained from explicit condemnation. In many cases, a similar attitude regarding biologists and managers was apparent. Biologists generally were accused of systematically underestimating population sizes in order to secure research funding, and because they simply were some kind of "professional environmentalists."

Many informants, however, seemed to have very vague ideas about biologists and managers, and confined themselves to general statements about "city people" and "bureaucrats" in general. The following sequence is taken from a focus group with 18-yearold males undergoing vocational training in a traditional male craft; all are eager hunters (and note that sheep are not mentioned even once):

Int: Are there too many of all kinds of predators?

A: Yes, I think so.

B: The wolves are the worst, they spread faster and faster.

$\mathrm{C}$ : Wolves are dangerous!

B: When they ... say that there are only so many wolves, the figures aren't right.

Int: No? Who are you talking about?

B: It's these scientists and those people...

C: It's scientists who make money from it!

B: They say there are perhaps two, or a pair, so that makes four or five [meaning a family group], but then they could multiply that by two or three. Then they would be getting closer. 
C: If they had only said 20 or 30 !

(...)

Int: Do you know any names, people who have been exposed in the media-for instance, in connection with the predator issue?

B: Predators, that would be, what's his name, $\mathrm{X}$ [spokesman for a group called "Our Carnivores" (Våre Rovdyr)].

C: There's a couple that need a good beating!

A: And then there is that other one, what's his name?

[Silence]

Int: No, it doesn't matter. But what do you think of people like $X$ ?

B: He doesn't know what he is talking about, to put it that way.

C: Actually, we should feel sorry for him.

A: He's sick in his head! (laughs)

B: If he had lived here and sort of been into the problems, then perhaps it would have been something else.

The young hunters conveyed an impression of having substantial knowledge of the outdoors and of nature in the region. This was not scientific knowledge, however; it stemmed from their own experience and the experience and interpretations of other hunters and outdoorsmen. They constantly attacked the biologists' estimates of the carnivore population. And indeed, the extensive experience of these young hunters should not be underestimated. In some instances, their judgment is probably just as sound as that of biologists, who have not had the advantage of growing up in these woods.

Here we also touch on the issue of trust in different information providers. There is no question about who was trusted: the hunters whom they knew and saw as fellow contributors to an accumulation of real, solid knowledge (as opposed to academic speculations); such knowledge is not only useful but also reinforces their identities as practical, tough woodsmen and as downto-earth producers of real things (whether timber, game, houses, or styled cars). Such practically founded, lay knowledge does not exclude environmental concern, however. It merely takes its own form, rooted precisely in extensive firsthand knowledge of material conditions. 
Indeed, it is characteristic that the only informants who mentioned current logging practices as a problem (although not labeled "environmental") belonged to this group. These informants also revealed a knowledge of the ecological harm that logging may cause. The following sequence is taken from the same group as the last quotation:
A: They should reduce some of the logging they do here, that's for sure.
Int: What about it?

A: They destroy the populations of wood grouse [large forest fowl that need old-growth forest].

Int: Yes, I think many would agree with you. Are there other things?

B: Cut out the machinery, and use horses like in the old times! The clear-cuts are much too large, they ruin everything.

A: They make these big ugly furrows.

Int: But is this something you think about regularly when you are out hunting?

A: I do, yes. It gets so difficult to walk across the clear-cuts.

B: And they have ruined important mating habitat for the wood grouse.

Int: But hasn't this improved a little lately?

A: No, it's only getting worse all the time.

In the "pro-carnivore camp" we find a different set of background factors. These young people came from middle-class families, and were themselves oriented towards distinctly modern occupations, mostly through academic education. Not everyone came from a humanistic-social background (see note 1), but most had at least one parent in such a position. These informants identified strongly with modern cultural trends and related perspectives on nature, and actively rejected what they viewed as local redneck culture. They often spoke scornfully of the boys who belonged to what they regarded as a kind of hunting-and-fishing subculture, and considered them rather simple and a little backward. Similarly, they held critical opinions of sheep farmers; they viewed them as irresponsible (sending sheep out to die, not only from depredation but also from accidents) as well as stubborn and lazy (not willing to herd their sheep actively).

The first two speakers are 19- and 20-year-old males, culturally 
very modernist. One was about to enter university-level education, and the other was in academic training; both had parents in the public-sector middle class.

A: When I went to school here, there were frequent clashes with those who lived on farms and had animals; they saw these things in a completely different way than us who (...) had never been in contact with animals, and wanted very much to protect the bears. There are still many who are very much engaged in that issue. (. . .) I used to be very much in favor of the carnivores.

B: I still can't imagine how any responsible person can send sheep out in the forest without looking after them properly. You might think that they actually want them to get killed.

Int: Why would they want that?

B: Perhaps to get the compensation? But I guess we can't think that way about them. They can't be that extreme.

In the next selection we hear from a 16-year-old girl, a classical musician in an academic program, and an 18-year-old boy, a brass band musician in vocational training (but leading to a distinctly modern occupational niche); both have parents in the publicsector middle class.

A: Yes, I do have an opinion. I do not think they should be shot. There are so few wolves in the world. It's a . . . what's it called ... an endangered species. OK, they kill some sheep, and then those people ... they could really look after their sheep. Then they say that it is so expensive [to look after them]. But they lose sheep if they don't look after them, and that must be just as expensive, if not more so. And they won't get compensation for that [nondepredation accidents that could have been prevented by shepherding]. And the wolves . . . that's only an instinct they have got.

B: If they start shooting them, and then there are suddenly only a few left in the world, then they would surely regret it ... In Rumania there are 2,500 wolves, and probably more sheep than here. But there they have hired shepherds to look after the herds. I think they could do that here too, instead of shooting the poor wolves. I think the wolves should be left in peace.

These perspectives on the carnivore issue obviously stemmed from sources other than those of the hunters: namely, from the media 
and from significant (nationally exposed) proponents of carnivore protection. That is, these informants had adopted a perspective on nature which stemmed largely from nonlocal sources. This is corroborated by their focus on sheep depredation as a core issue. Sheep farming is now of limited economic importance in Trysil, but it is definitely the aspect of the carnivore conflict with the greatest media exposure. We saw that the young working-class hunters concentrated on conflict issues within their own field of experience, and this rarely included lost sheep. The pro-carnivore faction, however, had only very limited firsthand knowledge of the conflict's subject matter, and thus took images from external sources as their point of departure.

Insofar as their understanding grew out of their own interaction with nature, this position reflected the character of their outdoor recreational activities. These were usually not consumptive, but typically were pursuits such as snowboarding, skiing, and nature photography. A few of these informants held political views very far to the left, and told about many clashes with "carnivore haters" over the years (although they stressed that they now had a more mature and more nuanced understanding of "the other side"). None of them, however, had ever been a member of an environmental organization. Even though they identified strongly with the cause of the environmental movement, and were at least moderately knowledgeable about the carnivore issue, they knew little of Norwegian environmental organizations.

\section{The Alienation of Lay Knowledge: Cultural Hegemony and Resistance}

It seems that continuing reproduction of class-related cultural forms leads to a persistent cultural cleavage among young people. Thus my findings point in the same direction as other studies that have found such continued reproduction (see Eckert 1989; Jørgensen 1994; Skogen 1998; Weis 1990). In the present context, two interwoven dimensions appear to be particularly significant in an analysis of this cultural cleavage: the power relations between scientific and lay knowledge, and the relationship between cultural hegemony and resistance.

\section{Forms of Knowledge}

Although the relation between the environmental movement and dominant science is sometimes construed as one of conflict (see Beck 1992; 1995), this is at best an incomplete understanding. The predominant environmental discourse is powerfully informed by science, and environmentalists regularly claim a scientific basis for their arguments. This prominence of scientific understandings is no surprise when we consider the middle-class basis of the environmental movement (Cotgrove and Duff 1980; Eckersley 1989; 
Kriesi 1989; Morrison and Dunlap 1986; Skogen 1996). Environmental management agencies, of course, are also staffed almost exclusively by academics; this helps to generate a discourse that is largely shared with the environmental movement. Although emphasis may differ considerably, there is generally a common conceptual ground that appears to provide a familiar, comfortable frame for the exchange of diverging opinions. Thus the confusion of environmentalists, biologists, and managers found in particular in Trysil's outdoorsman culture actually reflects reality to a substantial degree.

Dickens (1996) states that the division of labor in modern societies has led to a removal of people from nature, both as producers and as consumers, and to a general fragmentation of knowledge, which severely affects our understandings of nature. According to Dickens, a highly significant aspect of the division of labor is what Braverman (1974) termed the separation of conception from execution. This means that scientific knowledge has been separated from lay knowledge gathered through concrete experience. This separation will necessarily affect the relationship between environmentalists, environmental managers, and scientists, on the one hand, and on the other, people who possess knowledge about nature which they obtained through everyday practices, but which is neither molded into forms that are recognized by science nor furnished with the institutional foundation necessary to obtain such recognition.

The alienation of lay knowledge is a consequence of people's knowledge being taken away from them. Lay knowledge is rarely taken seriously by certified experts, and is frequently ridiculed. Lay knowledge itself is complex, however. It may be intrinsically complicated and advanced on its own terms, as is the case with knowledge systems that are built up over a long time. It is also frequently merged with scientifically based knowledge. Nevertheless, we perceive here a social division of knowledge, in which the hegemonic position of scientific knowledge in relation to other forms of knowledge is an important dimension of the separation of scientific knowledge from these other forms.

The technological advances that have been vital to the development of capitalism originated from a science which has largely been integrated into capitalist economy. Thus the centrality of technological development and (in the twentieth century) the attempts at scientific social engineering have reinforced the dominance of scientific knowledge over lay, tacit knowledge. The emergence and rapid growth of the modern middle class has also been very important in this respect. Claims to a monopoly over socially useful (scientific) knowledge have been fundamental to middleclass strategies for carving out new and advantageous social posi- 
tions. The middle class' active construction of an incessantly growing need for such knowledge in every conceivable area of human life has been an important force behind the dramatic expansion of this class throughout the era of industrial capitalism (Martin 1998).

In Trysil, the young working-class hunters offered cultural resistance by actively defending practical experience and ridiculing academic knowledge and academics. They even accused the latter of dishonesty and manipulation. The pro-carnivore middle-class youths, on the other hand, relied more strongly on external knowledge, ultimately based on science and conveyed through a dominant media discourse.

The environmental movement generally emphasizes the interdependence between humans and nonhuman nature, and the need to recognize humans as part of nature. In practice, however, environmental groups frequently end up advocating a separation between people and their natural surroundings, in order to protect nature from damage caused by humans. Politically this perspective may be different from the dominant ideology in modern societies; as a mode of understanding nature, however, it is not. Again, this point shows the overlap between green ideology and hegemonic forms of knowledge, and the corresponding distance between such forms of understanding and the lives and experiences (and ensuing knowledge) of those segments of the population that are farthest removed from dominant, scientific knowledge.

A notion that "we should not meddle with nature" is very distant from a relationship to nature based on everyday physical interaction with it. Such concrete interaction may facilitate perspectives on material production and on the necessary exploitation of natural resources that are more realistic, in a sense, than perspectives founded primarily on scientific knowledge. On the other hand, physical interaction with nature is no guarantee of a sustainable management of these resources, much less of a deeply felt unity with nonhuman nature. Quite the opposite is true in many instances, as demonstrated by the confluent views on environmental issues frequently held by capital and by workers (see Aardal 1993; Hanson 1995). The point, however, is that a relationship to nonhuman nature based on the physical manipulation of that nature is no weaker or no less appropriate a foundation for developing understandings and practices that lead towards sustainability. This is obviously true even if sustainability is given a strong ecocentric meaning, because humans must interact with the rest of nature and must utilize its resources, just like any other species. In Trysil, the young anti-environmentalist hunters felt a deep concern about the effects of modern forestry, and they had firsthand knowledge to support their criticism. 


\section{Cultural Hegemony and Resistance}

Schisms originating from the tension between scientific knowledge and lay, tacit knowledge will overlap and merge with conflicts stemming from tensions between hegemonic and subordinate cultural forms. Such overlap is not perfect, but hegemonic cultural forms generally coincide with or subsume scientific forms of knowledge; in contrast, in subordinate cultural forms, practically founded knowledge occupies a pivotal position.

Reporting from a study of forest workers in Canada, Dunk observes:

Working-class culture in northwestern Ontario is based upon common sense and anti-intellectualism as forms of thought. This is not peculiar to the male working class or the regional culture. . . . However, common sense and antiintellectualism have particular resonances and ideological effects in a regional economy historically heavily reliant upon resource-extraction industries and a regional division of labor which correlates, to an extent, with a division between mental and manual labor. (Dunk 1994:19)

The point Dunk makes here is that the tension between academic and lay knowledge and between hegemonic and subordinate cultures is part of a larger pattern of regional and class conflicts. The dominant culture, of course, is situated within the upper and middle classes. Whereas the position of the middle class relative to relations of exploitation and power is generally considered to be diverse as well as ambiguous (Savage et al. 1992; Wright 1997), the material and social conditions facing the middle class have not developed cultural forms essentially different from those penetrating the hegemonic institutions of modern society (Bourdieu and Passeron [1977] 1990). On the contrary, the size of the middle class and its conspicuous position within these institutions turn its members into even more visible bearers of dominant culture than members of the upper class. In addition, in view of the predominant social and cultural basis of the environmental movement, it seems obvious that environmental issues will enter a complex field of established antagonism.

The environmental movement and environmental management agencies seem to display a "know-all," patronizing attitude, rooted in a claim of superior knowledge. Such an attitude is recognized easily, and may generate rejection of the problem definitions and perspectives of organized environmentalism and environmental science at large. In most cases, this rejection must be seen as forms of cultural resistance (Dunk 1991; Willis 1977).

The social construction of the urban-rural conflict axis plays an 
important part here. Those groups, institutions, views, and indeed ways of life which are perceived as threatening or disturbing, undermining fundamental interpretations of nature and even "the world at large," are more prevalent and definitely more visible in urban areas. This sense of cultural conflict blends with the experience of economic centralization, depopulation, and a declining level of service in marginal areas-and of course with the experience of dead sheep and fewer roe deer. Therefore urban people, urban culture, and indeed cities as such are convenient, instantly recognizable symbols of the forces behind the problems confronting rural people.

Dunk's study demonstrated that Ontario forest workers were deeply concerned about the state of the forest, and saw clearly the harmful effects of current logging practices. Many of their ideas about logging corresponded closely to those held by environmental organizations. The workers, however, viewed environmentalists as alien and irrelevant, representing lifestyles and ideologies so distant that they appeared to serve an important function as outside others against which the forest workers constructed their own identities. This seems to be the same picture as we saw in regard to the young working-class hunters in this study. Dunk found that the environmental organizations did little to approach the forest communities. The organizations generally seemed to hold on to the traditional middle-class image of working people as rough and unsophisticated, unable or unwilling to "approach nature with the appropriate level of reverence and awe" (Dunk 1994:18). Instead, working-class people were seen as using nature in violent and disagreeable ways:

To the horror of animal rights activists and eco-tourists, [the workers'] interaction with nature is heavily mediated by technology and much of the leisure enjoyment of nature does involve appropriating it rather violently, thereby reflecting the relationship with nature entailed in logging. All of this is inextricably bound up with local ways of constituting a "masculine" identity. (Dunk 1994:22)

A physical masculinity has been delineated as a staple element in male working-class culture, emphasizing strength, daring, and practical knowledge and ingenuity (Dunk 1991; Hall and Jefferson 1976; Robins and Cohen 1978; Skogen 1998). This masculine ethos is also embedded in many forms of outdoor activities, not least in hunting, which is an ideally suited medium for this cultural trait (Skogen and Wichstrøm 1996). In Trysil, the outdoorsman culture was bound tightly to such expressions of masculinity. The attitudes toward hunters and farmers held by some middle- 
class youths is culturally akin to the horror felt by the (no doubt middle-class) groups to which Dunk refers.

Earlier work identified the polarization between an abstractionoriented culture and a production-oriented culture as salient to the understanding of class cultural diversification of environmental orientation (Skogen 1996). The patterns that emerged in Trysil indicate that such polarization persists among young people, and within a rural community. The abstraction-oriented culture that prevails in the middle class is based in sectors of society where the dominating pursuit is the manipulation of symbols, not material objects. Abstraction and aesthetization are related processes (Bourdieu 1984); both relate to concepts of nature in important ways. The abstraction-oriented culture will provide a disposition towards aesthetic evaluation of nature, as well as identification with abstract totalities (e.g., all living things, our planet, mother earth). Aesthetization plays a part when unspoiled wilderness is contrasted with humankind's harmful manipulation of nature.

The production-oriented culture prevails among people close to the business end of material production. Skepticism towards abstraction and towards people involved in intellectual pursuits is deeply embedded here (Gullestad 1984; Lysgaard [1961] 1976). Abstract holism will probably fall on rather barren soil in a culture hostile to abstractions. It seems likely that the production orientation itself will influence attitudes towards exploitation of nature, in the sense that the untouched will not necessarily be valued in itself. If creativity is linked conceptually to material production, it is not altogether a bad thing that it leaves some traces.

\section{Effects of Modernization}

The social forces of late modernity apparently have influenced young people's relationship to the carnivore conflict by removing a larger proportion of them from the economic sectors that are affected most strongly. Thus they are left open to interpretations not derived primarily from either sheep farming, traditional resource extraction, or traditional outdoors culture-or indeed, they are left with hardly any interpretation at all.

The expansion of middle-class groups where strong pro-carnivore sentiments have a fertile cultural ground, even in rural areas, is a distinctly modern development. This is the case even if there is nothing new in the cultural polarization itself. Yet the growth of such groups, and the related surfacing of perspectives on nature that previously were extremely marginal in rural areas, indeed represent a cultural shift.

Conversely, structural change also has induced what we might term a "compressed" working-class culture. A shrinking proportion of the rural population belongs to the manual classes, and 
even fewer are engaged directly in any form of resource extraction or livestock farming. Further, the options for young people from such a background have multiplied. Today they are subject to less pressure to stay in these economic segments. Indeed, there may be few openings for those who want to stay. Thus, when research has demonstrated that many young people make traditional choices at critical points on their way through the educational system, these are now actually choices. Accordingly, the adherence to traditional cultural forms is also more of an active choice today than in the past: many young people now drift away from this way of life. This seems to bring about a certain "subculturalization" of traditional mainstream values. Yet the frequently expressed concern about marginalization and social exclusion of these groups, particularly those who cherish a masculine ethos viewed by many as archaic in late modernity, may well be exaggerated. At least this questions remains to be investigated empirically. In Trysil I received the impression that these were vital milieus with a high quality of life, despite the cultural pressure.

We must not forget, however, that some of those who were deeply rooted in the outdoorsman culture were only moderately critical of current carnivore management, or even supported it. Factors conducive to such positions appeared to be choice of academic programs in secondary education, educational ambitions beyond secondary school, and degree of general "outward-orientedness." Thus processes of modernization may be said to eat away at the edges of the typical outdoorsman culture, even while they probably strengthen the resistance efforts at its core.

\section{Conclusion}

Class-related cultural patterns and forms of knowledge still seem to be operative in shaping young people's perspectives on environmental issues such as the carnivore conflict. However, the production-oriented culture and its inherent forms of practically founded knowledge are probably restricted to smaller groups of young people than before. The same is true of cultural resistance to hegemonic forms of knowledge. This situation is due to increasing mobility away from manual production and cultural forms typically associated with it. Such trajectories have weakened the ties not only to the economic sectors most strongly affected by the carnivore problems, but also to ways of life that may be losing ground, particularly traditional forms of hunting, fishing, and use of nature. These processes have become open to significantly increased cultural influence from other sources. A substantial group of young people seems to be detached from the whole issue because of their lack of contact with the conflict and its subject mat- 
ter, as well as their orientations away from traditional land use and ways of life.

In addition, although the polarization between class cultural forms and between corresponding views on environmental issues (at least the carnivore question) seems to be quite intact, it now appears in what we might term a "compressed" mode. This compression or "subculturalization" of traditional cultural forms may lead to strategies of resistance that intensify the cultural polarization which future management regimes must address. Therefore these mechanisms appear to be quite important to policy development and implementation, both in the field of carnivore management specifically and in nature management generally.

\section{References}

Aardal, B. 1993. Energi og miljø (Energy and the Environment). Oslo: Institute for Social Research.

Beck, U. 1992. Risk Society: Towards a New Modernity. London: Sage.

1995. Ecological Politics in an Age of Risk. Cambridge, UK: Polity.

- 2000. "Living Your Life in a Runaway World: Individualisation, Globalisation and Politics." Pp. 164-74 in On the Edge: Living with Global Capitalism, edited by W. Hutton and A. Giddens. London: Jonathan Cape.

Bjerke, T., O. Reitan, and S.R. Kellert. 1998. "Attitudes Toward Wolves in Southeastern Norway." Society and Natural Resources 11:169-78.

Bourdieu, P. 1984. Distinction. London: Routledge.

Bourdieu, P. and J.-C. Passeron. [1977] 1990. Reproduction in Education, Society and Culture. London: Sage.

Braverman, H. 1974. Labor and Monopoly Capital: The Degradation of Work in the Twentieth Century. New York: Monthly Press.

Bynner, J., E. Ferri, and P. Shepherd, eds. 1997. Twenty-Something in the 1990s: Getting On, Getting By, Getting Nowhere. Aldershot: Ashgate.

Corrigan, P. 1979. Schooling the Smash Street Kids. London: Macmillan.

Cotgrove, S. and A. Duff. 1980. "Environmentalism, Middle-Class Radicalism, and Politics." Sociological Review 2:333-51.

Dickens, P. 1996. Reconstructing Nature. London: Routledge.

Dunk, T.W. 1991. It's a Working Man's Town. Montreal: McGill-Queen's University Press.

- 1994. "Talking About Trees: Environment and Society in Forest Workers' Culture." Canadian Review of Sociology and Anthropology 31:14-34.

Echeverria, J.D. and R.B. Eby, eds. 1995. Let the People Judge: Wise Use and the Private Property Rights Movement. Washington, DC: Island Press.

Eckersley, R. 1989. "Green Politics and the New Class: Selfishness or Virtue?" Political Studies 2:205-23.

Eckert, P. 1989. Jocks and Burnouts: Social Categories and Identities in the High School. New York: Teachers College Press.

Feathersone, M. 1992. Consumer Culture and Postmodernism. London: Sage.

Foster, J.B. 1993. "The Limits of Environmentalism Without Class: Lessons From the Ancient Forest Struggle of the Pacific Northwest." Capitalism, Nature, Socialism 4:11-41.

Furlong, A. and F. Cartmel. 1997. Young People and Social Change. Buckingham: Open University Press.

Gullestad, M. 1984. Kitchen-Table Society. Oslo: Universitetsforlaget. 
Hall, S. and T. Jefferson, eds. 1976. Resistance Through Rituals: Youth Subcultures in Post-War Britain. London: Hutchinson.

Hanson, L. 1995. "Turning Rivals Into Allies." Alternatives 21:26-31.

Hegna, K. and H. Helland. 1998. Ung $i$ Bergen. Om skoletilpasning og problematferd $i$ videregdende skole (Young in Bergen: School Adjustment and Conduct Problems in Upper Secondary School). Oslo: NOVA.

Jørgensen, G. 1994. To ungdomskulturer. Om vedlikehold av sosiale og kulturelle ulikheter $i$ Bygdeby (Two Youth Cultures: Maintaining Social and Cultural Boundaries in Bygdeby). Sogndal: Vestlandsforskning.

Kalland, A. 1993. "Management by Totemization: Whale Symbolism and the AntiWhaling Campaign." Arctic 46:124-33.

Kaltenborn, B.P., T. Bjerke, and E. Strumse. 1998. "Diverging Attitudes Towards Predators: Do Environmental Beliefs Play a Part?" Research in Human Ecology 5:1-9.

Kriesi, H. 1989. "New Social Movements and the New Class in the Netherlands." American Journal of Sociology 94:1078-1116.

Lysgaard, S. [1961] 1976. Arbeiderkollektivet (The Workers' Collective). Oslo: Universitetsforlaget.

Martin, B. 1998. "Knowledge, Identity and the Middle Class: From Collective to Individualised Class Formation?" Sociological Review 45:653-86.

Melucci, A. 1996. "Youth, Time and Social Movements." YOUNG, the Nordic Journal of Youth Research 4:3-14.

Morrison, D.E. and R.E. Dunlap. 1986. "Environmentalism and Elitism: A Conceptual and Empirical Analysis." Environmental Management 10:581-89.

Pollock, G. 1997. "Individualization and the Transition From Youth to Adulthood." YOUNG, the Nordic Journal of Youth Research 5:55-68.

Robins, D. and P. Cohen. 1978. Knuckle Sandwich: Growing Up in the Working Class City. Harmondsworth: Penguin.

Savage, M., J. Barlow, P. Dickens, and T. Fielding. 1992. Property, Bureaucracy and Culture. London: Routledge.

Skogen, K. 1996. "Young Environmentalists: Post-Modern Identities or MiddleClass Culture?" Sociological Review 44:452-73.

- 1998. "A Touch of Class: The Persistence of Class Cultures Among Norwegian Youth." YOUNG, the Nordic Journal of Youth Research 6:15-37.

- 1999. "Another Look at Culture and Nature: How Culture Patterns Influence Environmental Orientation Among Norwegian Youth." Acta Sociologica 42:223-39.

Skogen, K and L. Wichstrøm. 1996. "Delinquency in the Wilderness: Patterns of Outdoor Recreation Activities and Conduct Problems in the General Adolescent Population." Leisure Studies 15:151-69.

Weis, L. 1990. Working Class Without Work. New York: Routledge.

Willis, P. 1977. Learning to Labour. Aldershot: Gower.

Wright, E.O. 1997. Class Counts. Cambridge, UK: Polity. 